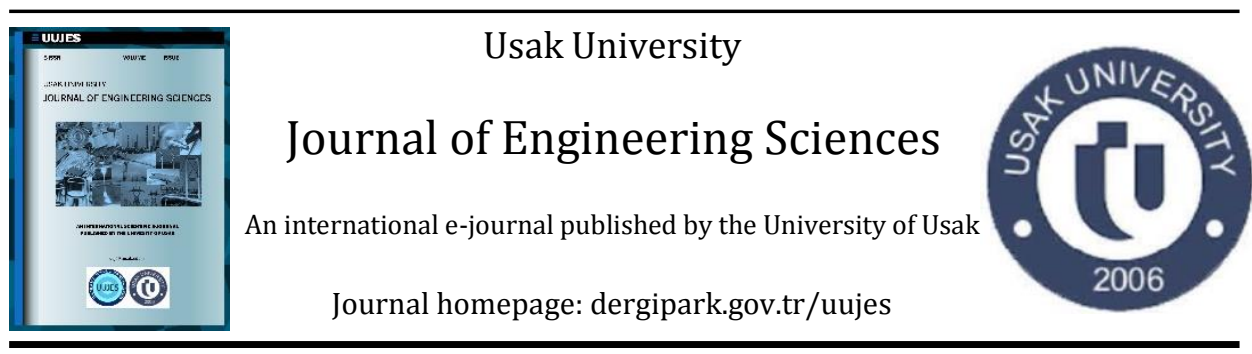

Research article

\title{
SUBJECTIVE EVALUATION OF TOWEL QUALITY PERCEPTION ACCORDING TO THE EXPERTS' AND NON-EXPERTS' VIEWPOINT
}

\author{
Gülşah Susurluk1*, Yüksel İkiz², Erkan Türker \\ ${ }^{1}$ Textile Technology Department, Associate's Degree Vocational School, Beykent University, Istanbul, Turkey \\ ${ }^{2}$ Faculty of Engineering, Textile Engineering Deparment, Pamukkale University, Denizli, Turkey \\ ${ }^{2}$ Faculty of Engineering, Textile Engineering Deparment, Usak University, Usak, Turkey
}

\begin{abstract}
In this study, subjective evaluation of towel samples with distinctive fiber contents was investigated. The subjective evaluation questionnaire was performed both by experts with professional experience in the towel sector and by non-experts in this sector. The evaluation was conducted by 30 experts (18 males and 12 females) and 30 non-experts (17 males and 13 females). The experts and non-experts were asked this question: "Could you state parameters that define towel quality with the exception of color and pattern?". Each expert and non-expert had to mention at least 3 parameters. During the evaluation phase, they could visually experienced the color of all towel samples and the information were given about the features like fiber content, yarn count, grammage etc. By touching all samples, towel quality perceptions of the parameters specified for each sample were evaluated subjectively by experts' and non-experts' viewpoint.
\end{abstract}

Keywords: Towel; towel quality perception; subjective evaluation; expert; non-expert.

(C)2020 Usak University all rights reserved.

\section{Introduction}

Subjective evaluation is used in many sectors to determine the preferences of consumers. The perception of touch properties of a textile product is significant for consumer choice, in this way, consumers can have a vision that cannot be handily found with the vision sense [1-13]. In the simplest terms, it is difficult to perceive with the eye, however, touch properties such as softness, toughness, density, driftiness, smoothness, roughness, weight, thickness, etc., which can be interpreted when touched, have a very important place in the preferences of consumers [1-11, 14-17]. In the case of studies on consumer

*Corresponding author: Gülşah Susurluk

E-mail: gulsahsusurluk@beykent.edu.tr / gulsah.susurluk@gmail.com (ORCID: 0000-0003-3284-2248)

DOI: $10.47137 /$ uujes.790395

(C)2020 Usak University all rights reserved. 
behavior, this phenomenon was investigated and confirmed many times $[1,2,4,7,8,11$, $13,18,19]$.

Properties based on a visiul and tactile inspection in a short time are evaluated as subjective properties. As this method is fast and practical, it continues to be used all over the world for the fabric hand valuation properties, especially for the fabric quality perception evaluation $[5,7,9,11,12,20,23]$.

Therefore, in most of the studies related to tactile properties, it is seen that evaluations called "subjective' 'are used by people without using an instrument or device [24].

In the textile industry, individuals or small groups (such as purchasing department officials) control the tactile properties of the fabric when deciding whether it is suitable for use. Individually (jury members or evaluators) or evaluation groups (panels) are used in researches to determine these properties. The studies that started with Binns for the first time in 1926 for subjective evaluation of tactile properties are still continuing today. According to Binns; The subjective evaluation of fabrics made with a group of people who are experienced, knowledgeable about the subject they are examining is a more and practical, it continues to be used all over the world in the evaluation of fabric handle properties, especially in the evaluation of fabric quality perception $[5,7,9,11,12$, 20-23].

In the textile industry, individuals or small groups (such as purchasing department officials) control the tactile properties of the fabric when deciding whether it is suitable for use. Individually (jury members or evaluators) or evaluation groups (panels) are used in researches to determine these properties. The studies that started with Binns for the first time in 1926 for subjective evaluation of tactile properties are still continuing today. According to Binns; The subjective evaluation of fabrics made with a group of people who are experienced, knowledgeable about the subject they are examining is a more realistic and sensitive sorting than the evaluation of a single person [14, 24, 25]. Since the perception of tactile properties can vary from person to person and this concept is influenced by factors such as climatic conditions, cultural structure, age and gender of the person, the way the juries are formed is very important.

These properties, which directly affect the subjective evaluation results, should not be ignored, as well as the fact that jury members are formed by experts (who have knowledge or experience on the subject) or non-experts. In addition to researchers Brand [26], Dawes and Owen [27], Howorth and Oliver [27], David and others [27] who made studies on subjective evaluation of tactile properties, Kawabata and Niwa's [28-30] researchs have also contributed to this study. Some of the researchers, such as Matsuo, while working mostly with experts, some of them did not discriminate between experts and non-experts when forming the jury and took this into consideration during the examination phase of results $[14,31]$. The work carried out by Kawabata and his friends in 1972 to standardize the fabric handle and quality perception evaluation criteria by forming the Attitude Evaluation and Standardization Committee in Japan has an important place in the world literature today [29]. The subjective descriptors that came to an important place in the world literature by Kawabata et al., which were initiated to standardize the fabric handle and quality perception evaluation criteria, are softness, fullness, hardness, smoothness, surface appearance and other properties [28, 29]. Evaluation criterias, which have an important place in the world literature, are used by different researchers by being translated into English or their own language. As a result of the researchers, the first expressions perceived as the subjective characteristics of the fabric were determined as in Table 1. 
Table 1 Japanese and English equivalents of the initial handle statements perceived as subjective characteristics of the fabric $[28,29]$

\begin{tabular}{cc}
\hline JAPANESE & ENGLISH \\
\hline NUMERI & Smoothness \\
SHARI & Crispness \\
KOSHI & Stiffness \\
HARI & Anti-Drape Stiffness \\
FUKURAMI & Fullness and Softness \\
& Surface Appearance and Other Properties \\
& Scrooping Feeling \\
KISHIMI & Flexibility with Soft Feeling \\
SHINAYAKASA & Soft Touch \\
SOFUTASA & Crepe-Like \\
TEKASA & \\
\hline
\end{tabular}

In addition, the inital research for the textile product's tactile properties was studied in Turkey in 2006 by Sular and Okur with a panel of 18 experts [32]. Until then, many similar studies have been conducted on subjective evaluation of tactile properties [12]. Although researchs on the subjective valuation of the perception of touch sense for the textile fabrics, there is little research based on the subjective evaluation of quality perception features of terry fabrics. In the study carried out by Singh, Behera and Matsudaira [22], with 25 experts defined the properties that affect towel quality. Nishimatsu et al. [33], when a towel was touched by non-experts, it was tried to find the parameters that best represent it. Kandzhikova et al. [5] based on a study among 28 experts and consumers, the properties that affect the quality of the towel fabric were evaluated subjectively. Ikiz et al. [13] examined the subjective evaluation of 10 towel samples made of different fiber content visually and tactically. Although Turkish towel users do not know the fiber content, It has been observed that they prefer towels made of synthetic yarns more than $100 \%$ cotton, but if they know the fiber content, they prefer $100 \%$ cotton by far. In the study by Ala and İkiz [34], the effect of selected fabric structural parameters and domestic laundering operations on acceptable woven towel product quality for both purchasing and daily use was investigated. As a result, weft yarn number, weft density and repeated washings were identified as important factors affecting the softness and preference of terry fabrics. Yuriko et al. [35] presented new parameters to characterize changes in pile structure, which are closely related to the tactile comfort of towels. Tactile evaluation of 16 cotton towel samples washed in different numbers was made. As a result of tactile evaluation, tactile comfort was associated with softness and smoothness, geometric roughness (SMD) and compression linearity (LC), while no significant relationship was observed between compression energy (WC).

Denizli is one of the most important towel production location in the world. For this reason, it is very easy to access a wide range of towel samples with many experts who will determine the towel quality subjectively and with a wide range of production parameters. In this study, towel quality perception measurement was applied separately to the experts from Denizli who have professional experience in towel industry and other non-experts and the obtained data were compared. Unlike previous studies, expert group was determined with sensitivity both in quality and quantity. The expert group was 
composed of only representatives of the sector with a minimum of 5 years of professional experience in the towel sector, although those who were in the textile sector did not have experience in the towel field and those with academic backgrounds compared to sectoral experience were not included in the expert group. In addition, the number of experts has been kept at a high level to determine the parameters that best characterize the towel properties with high reliability. The results of the study provide a new viewpoint for the development of innovative products compatible with the needs of the consumer in the towel industry.

In this research, towel samples with distinctive characteristics were utilized. The samples were cut on a laser machine $20 \times 20 \mathrm{~cm}$ in size. Standart atmospheric conditioning were carried out for the towel samples for $24 \mathrm{~h}$ with temperature $20 \pm 2{ }^{\circ} \mathrm{C}$ and relative humidty $65 \pm 2 \%$ prior to the studies. All trials were conducted in same terms. For every participant, towel samples were put a plane and non-metallic surface incidentally after conditioning and application was carried out under the AATCC Evaluation procedure 5 [36].

\section{Method}

\subsection{Formation of subjective evaluation jury}

Total of 30 experts (18 males and 12 females) from 10 different companies in DenizliTurkey and total of 30 non-experts (17 males and 13 females) from İstabul-Turkey were participated to evaluate the perception of towel quality to this survey. In the selection procedure of the experts; the criteria of Malcolm Gladwell [37], which says that expertise in any subject is possible with a minimum of 10,000 hours of work experience on that subject, was considered. In the selection of non-expert participants, students from different departments were preferred. The average age of the experts was 39 , with the youngest being 28 and the oldest being 49 years old. The average experience of experts was 16,3 years with a minimum of 4 and a maximum of 31 years. The average age of the non-experts was 22 , with the youngest being 20 and the oldest being 25 years old. This survey was conducted in textile companies where experts work and in the university where non-experts study

\subsection{Application stage of subjective evaluation}

Regarding the subjective evaluation of the terry samples, the AATCC EP-5 directions were followed [34]. The experts and non-experts were asked this question: "Could you state parameters that define towel quality with the except for color and pattern?". Each expert and non-expert had to refer at least 3 parameters.

In addition, verification test protocol was conducted to experts and non-experts in order to ensure if their decisions are true. For this purpose, a pair of duplicate samples (Sample A and Sample B) were added in all samples. The factors affecting the towel quality was also measured simultanously on hidden duplicate samples to evaluate measurement precision. The responses of the experts and non-experts on duplicate samples were compared. In following stage, the expert and non-expert participants' parameters with same judgment were counted and calculation values were shown in percental based (\%).

The subjective evaluation period lasted a minimum of 30 minutes and a maximum of 110 minutes. The data set was gathered and the most chosen parametes from the point of towel quality was noted in order of priorities and the results were evaluated.

\section{Results and Discussion}


The parameters expressing the quality of towels were ranked by experts and non-experts as 1 st, 2 nd, 3rd and 4th parameters in order of importance. 22 out of 30 experts stated that the quality of towels could be evaluated with 3 parameters, while the remaining 8 experts expressed quality perception with 4 parameters, 28 out of 30 non-experts stated that the quality of towels could be evaluated with 3 parameters, the remaining 2 nonexperts evaluated quality perception with 4 parameters.

Subjective evaluations to estimate perception of fabric quality can be expressed in subjective descriptors [27, 30,38]. Although the diversity of subjective descriptors expresses perceptual substantiality; it is frequently encountered that some different subjective parameters are used to express common perception. As a result of this purely psychological event, it is natural that even the same sensory characteristics of people use words that are very close to each other in meaning but very different from each other [24]. Indeed our observations and discussions with experts showed that both handle and softness are used as identical concept. Likewise, observations and discussions with nonexperts showed that both softness and handle are used as identical concept. However in the literature hand or handle is a term resulting from the combination of many parameters such as softness, fabric texture structure, slipperiness, roughness etc. [27, 38].

As similar expressions were observed in the other definitions, necessary elimination and simplifications were made an according to the data supplied from experts and nonexperts, the parameters expressing towel quality are given in Tables 2-3.

The data in Tables 2-3 were showed how many times the total number of expert and nonexpert participants selected which parameter. For instance, in Table 2, the softness of the 1 st selected parameters was tabulated as $30 / 22$. This means that 22 out of a total of 30 experts were selected the softness parameter.

Table 2 Parameters expressing the perception of towel quality by experts

\begin{tabular}{|c|c|c|c|}
\hline $\begin{array}{l}\text { 1st selected } \\
\text { parameters }\end{array}$ & $\begin{array}{l}\text { 2nd selected } \\
\text { parameters }\end{array}$ & $\begin{array}{l}\text { 3rd selected } \\
\text { parameters }\end{array}$ & $\begin{array}{l}\text { 4th selected } \\
\text { parameters }\end{array}$ \\
\hline Softness $(30 / 22)$ & $\begin{array}{l}\text { Water absorbency } \\
(30 / 14)\end{array}$ & $\begin{array}{c}\text { Water absorbency } \\
(30 / 10)\end{array}$ & Trimness (30/5) \\
\hline $\begin{array}{c}\text { Water absorbency } \\
(30 / 5)\end{array}$ & Softness $(30 / 6)$ & Weight (30/7) & Naturalness $(30 / 1)$ \\
\hline \multirow[t]{5}{*}{ Yarn quality $(30 / 3)$} & Fullness (30/4) & Trimness (30/4) & Yarn quality (30/1) \\
\hline & Weight $(30 / 2)$ & Yarn quality (30/4) & $\begin{array}{c}\text { Water absorbency } \\
\qquad(30 / 1)\end{array}$ \\
\hline & Trimness $(30 / 2)$ & Fullness (30/3) & \\
\hline & Content (30/1) & Softness $(30 / 2)$ & \\
\hline & Yarn quality $(30 / 1)$ & & \\
\hline
\end{tabular}

As seen in Table 2, only 8 expressions (softness 30 times, water absorbency 30 times, trimness 11 times, yarn quality 9 times, weight 9 times, fulness 7 times, content 1 time, naturalness 1 time) were chosen by experts to define the perception of towel quality. Besides, Table 3 shows that 10 expressions (29 times softness, 15 times thickness, 12 times naturalness, 12 times trimness, 12 times water absorbency, 4 times quick dry, 3 times fullness, 2 times yarn quality, 2 times times durability) were selected by nonexperts.

Softness $(73 \%)$, water absorbency $(17 \%)$ and yarn quality $(10 \%)$, respectively, are the most important parameters stated by experts in determining the perception of towel 
quality. Softness (53\%), water absorbency (27\%), naturalness (13\%), and thickness (7\%), respectively, are also primary importance parameters expressed by non-experts. Kawabata et al. [28, 29], Singh et al. [22], Yuriko et al. [35] point out the perception of softness in the definition of the quality properties of a good towel fabric. The study results show consistency with relevant prior studies.

Table 3 Parameters expressing the perception of towel quality by non-experts

\begin{tabular}{cccc}
\hline $\begin{array}{c}\text { 1st selected } \\
\text { parameters }\end{array}$ & $\begin{array}{c}\text { 2nd selected } \\
\text { parameters }\end{array}$ & $\begin{array}{c}\text { 3rd selected } \\
\text { parameters }\end{array}$ & $\begin{array}{c}\text { 4th selected } \\
\text { parameters }\end{array}$ \\
\hline Softness (30/16) & Softness (30/9) & Trimness (30/11) & Trimness (30/1) \\
Water absorbency & Thickness (30/8) & Thickness (30/5) & 100\% Cotton $(30 / 1)$ \\
$(30 / 8)$ & Naturalness (30/4) & Softness (30/4) & \\
Naturalness (30/4) & Quick dry (30/2) & Naturalness (30/3) & \\
Thickness (30/2) & Yarn quality (30/2) & Fullness (30/2) & \\
& Water absorbency & Rapid drying (30/2) & \\
& Durability (30/1) & Water absorbency (30/2) & \\
& Fullness (30/1) & Density (30/1) \\
& Density (30/1) & \\
\hline
\end{tabular}

During the subjective evaluation, the dublicate samples were evaluated by all participants to determine consistency in the preferences of the participants. The results of this evaluation are illustrated in Figs. 1-2.

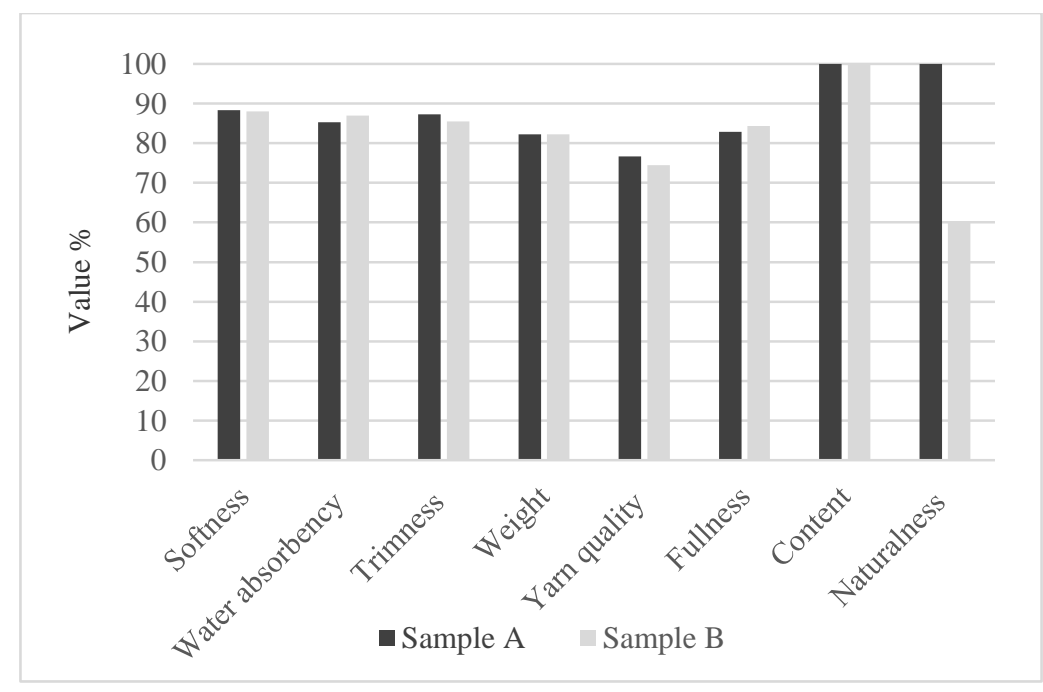

Fig. 1 Consistency percentages of the parameters selected by experts 


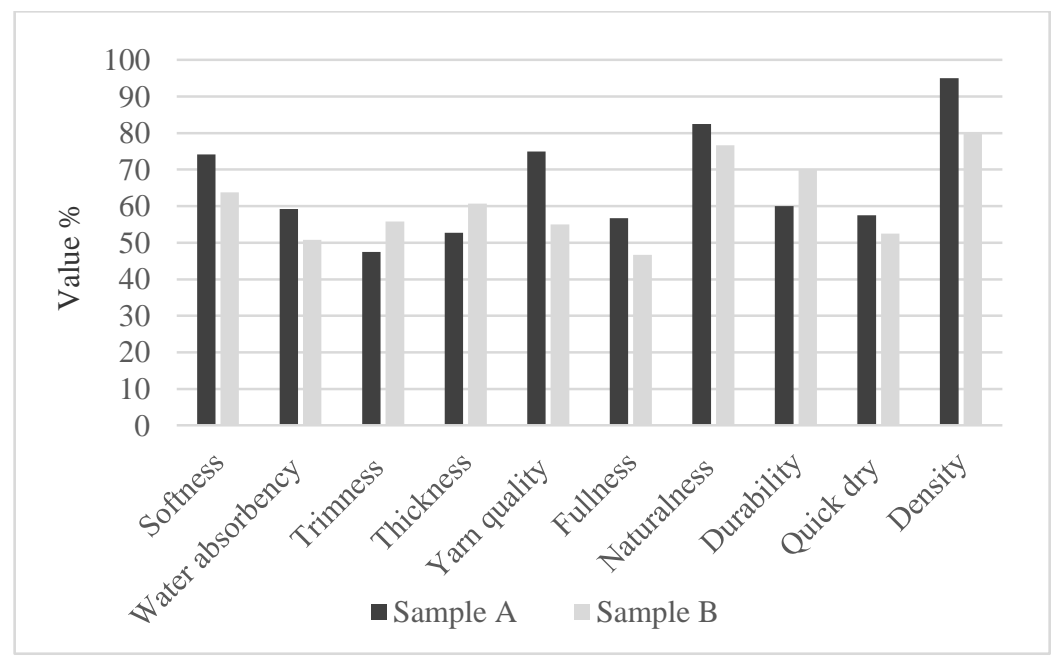

Fig. 2 Consistency percentages of the parameters selected by non-experts

Based on the verification test results presented in Figs. 1 and 2, the consistency rate of the softness parameter of the experts was $88 \%$ and $88.3 \%$ for the Sample A and Sample $\mathrm{B}$, respectively, while the consistency rate of the non-experts was $74 \%$ and $63 \%$. Consistency rates are higher among experts than non-experts. Total consistency rates were $85.25 \%$ for experts and $63.6 \%$ for non-experts. The reason why the consistency ratio of the experts is higher than the non-experts is thought to be due to the fact that the experts have professional experience in the towel sector and that the stability increases with the introduction of visual perceptions. Previous similar studies, also support this idea $[14,24,25]$.

\section{Conclusion}

In this study, it was tried to understand quality perception of towels by experts having minimum 10,000 hours of professional experience in towel industry and non-experts in this sector. The following conclusions can be drawn from this research:

- It was concluded that the most important towel characteristics which characterize the perception of towel quality in the best way are softness-water absorption and then, respectively, trimness, yarn quality, weight, fullnessbulkiness, content-naturalness by experts' viewpoint.

- By non-experts' viewpoint also, it was concluded that softness, thickness and then, respectively, naturalness-water absorption-trimness, quick dry, fullness, yarn quality-density, durability are the significant parameters in order of importance to define perception of towel quality.

Based on the comparison of towel properties by experts and non-experts which characterizes the perception of towel quality in the best way; it is expected that the parameters obtained as a result of the evaluation of the experts overlap with the subjective descriptors expressed by Kawabata, which makes an important contribution to the world literature and these significant parameters, which are specified by the experts, are expected to provide benefit towel manufacturers to direct their product development activities. 
In the next stage of the study, regression equation will be created separately for each quality parameter perceived as the subjective characteristic of towel fabric. Since the towel quality perception is primarily evaluated subjectively, then the regression equation will be developed for the TQV (Total Quality Value) by establishing a correlation between the data to be measured with the Kawabata KES system, which is located in KIT (Kyoto Institute of Technology) in Japan.

\section{Acknowledgement}

We would like to thank TUBITAK and DENIB for supporting the project number 1059B191700771.

*This article was produced from the PhD thesis titled "Determination and Development of Objective/Subjective Evaluation Criteria of Quality Perception in Towel Structures".

\section{References}

1. Chang S. Olfactory-tactile interactions and their implications for retailing, $\mathrm{PhD}$ Thesis, John Molson School of Business, Montreal, 2010.

2. Citrin AV, Stem DE, Spangenberg ER, Clark MJ. Consumer need for tactile input an internet retailing challenge. Journal of Business Research, 2003;56(1);915922.

3. Goett S. Linking threads of experience and lines of thought: Everyday textiles in the narration of the self, PhD Thesis, The University of East London, London, 2010.

4. Grohmann B, Spangenberg ER, Sprott DE. The influence of tactile input on the evaluation of retail product offerings. Journal of Retailing, 2007;83(2);237-245.

5. Kandzhikova GD, Germanova-Krasteva DS. Subjective evaluation of terry fabrics handle. The Journal of the Textile Institute, 2016;107(3);355-363.

6. Kergoat M, Giboreau A, Nicod H, Faye P, Diaz E, Beetschen MA, Meyer T. Consumer preference for tactile softness: A question of affect intensity? Journal of Sensory Studies, 2012;27(4);232-246.

7. Mahar TJ, Wang H, Postle R. A review of fabric tactile properties and their subjective assessment for next-to-skin knitted fabrics. The Journal of The Textile Institute, 2013;104(6);572-578.

8. McCabe DB, Nowlis SM. The effect of examining actual products or product descriptions on consumer preference. Journal of Consumer Psychology, 2003;13(4);431-439.

9. Nogueira C, Cabeco-Silva ME, Schacher L, Adolphe D. Textile materials: Tactile describers. Journal of Food Technology, 2009;7(3);66-70.

10. Pan N. Quantification and evaluation of human tactile sense towards fabrics. International Journal of Design \& Nature and Ecodynamics, 2007;1(1);48-60.

11. Sular V, Okur A. Sensory evaluation methods for tactile properties of fabrics. Journal of Sensory Studies, 2007;22(1);1-16.

12. Sular V, Okur A. Handle evaluation of men's suitings produced in Turkey. Fibres \& Textiles in Eastern Europe, 2008;16;61-68.

13. Ikiz Y, Sato T, Arık B, Matsumoto Y, Sarıkaya G. The effects of psychological manners on visual and tactile evaluation of towel preferences of Turkish and Japanese consumers. The Journal of the Textile Institute, 2017;108(7);11501156.

14. Ellis BC, Garnsworthy RK. A review of techniques for the assessment of hand. Textile Research Journal, 1980;50(4);231-238. 
15. Özçelik G, Süpüren G, Gülümser T, Tarakçığlu I. A study on subjective and objective evaluation of the handle properties of shirt fabric. Fibres \& Textiles in Eastern Europe, 2008;3(68);56-62.

16. Yıldız EZ, Özdil N. Subjective and objective evaluation of the handle properties of shirt fabric fused with different woven interlining. Tekstil ve Konfeksiyon, 2014;24(1);47-55.

17. Arık B, Ikiz Y, Çalışkan M, Karaibrahimoğlu K. Gömleklik kumaşların tuşe özelliklerinin duyusal analiz ve fiziksel test yöntemleriyle belirlenmesi ve aralarındaki ilişkinin değerlendirilmesi. Pamukkale Üniversitesi Mühendislik Bilimleri Dergisi, 2018;24(7);1262-1271.

18. Overvliet KE, Karana E, Soto-Faraco S. Perception of naturalness in textiles. Materials and Design, 2016;90;1192-1199.

19. Peck J, Childers TL. If I touch it I have to have it: Individual and environmental influences on impulse purchasing. Journal of Business Research, 2006;59;765769.

20. An SK, Gam HJ, Cao H. Evaluating thermal and sensorial performance of organic cotton, bamboo-blended, and soybean-blended fabrics. Clothing and Textiles Research Journal, 2013;31;157-166.

21. Luible C, Varheenmaa M, Magnenat-Thalmann N, Meinander H. Subjective fabric evaluation. International Conference on Cyberworlds, 2007;57;285-291.

22. Singh JP, Behera BK, Matsudaira M. Objective evaluation of terry fabric hand. The Journal of the Textile Institute, 2014;105(5);467-476.

23. Slater K. Subjective textile testing. The Journal of the Textile Institute, 1997;88(2);79-91

24. Sular V, Okur A. Kumaşların duyusal özelliklerinin belirlenmesinde subjektif değerlendirmenin yeri. Tekstil ve Mühendis, 2012;58;19-28.

25. Sular V. Kumaş tutumunun ölçülebilir kumaş özelliklerinden tahminlenmesi üzerine bir araştırma. Doktora Tezi, Dokuz Eylül Üniversitesi, Fen Bilimleri Enstitüsü, İzmir, 2005.

26. Brand RH. Measurement of fabric aestheties analysis is of aesthetic components. Textile Research Journal, 1964;791-804.

27. Bishop DP. Fabric sensory and mechanical properties. Textile Progress, 1996;6(3);5-27.

28. Kawabata S. The standardization and snalysis of hand evaluation. 2nd Edition, The Textile Machinery Society of Japan, Osaka, 1980.

29. Kawabata S. The development of the objective measurement of fabric hand. Proceedings of First Japan-Australia Symposium on Objective Spesification of Fabric Quality. Mechanical Properties and Performance, Kyoto, 1982;31-59.

30. Kawabata S, Niwa M. Clothing engineering based on objective ve measurement technology. International Journal of Clothing Science and Technology, 1998;263272.

31. Hallos RS, Burnip MS, Weir A. The handle of double-jersey knitted fabrics: Part 1: Polar profiles. Journal Textile Institute, 1990;81(1);15- 35.

32. Sular V, Okur A. Kumaşların duyusal özelliklerinin belirlenmesinde kullanılan subjektif değerlendirme yöntemleri. Tekstil ve Mühendis Dergisi, 2012;59;1421.

33. Nishimatsu T, Kanai H, Fujiwara M, Takahashi K, Kishine N, Fujita H, Furuta A, Masukawa A. Relation between hand of bath towel and physical properties. Journal of textile engineering, 2014;60(6);91-98.

34. Ala DM, İkiz Y. Subjective and objective evaluations of terry fabrics: Effects of structural parameters and repeated laundering. Tekstil ve Konfeksiyon, 2017;7(4);361-365. 
35. Yuriko K, Sachiko S, Hiroko Y. Tactile feel of washed towels and their compression and surface properties. Journal of Textile Engineering. 2019;65(6);97-103.

36. AATCC. AATCC Evaluation Procedure 5, Fabric hand: Guidelines for the Subjective Evaluation of. USA, 2011.

37. Gladwell M. Outliers. Mediacat Yayıncılık, 2016.

38. Kawabata S, Niwa M. Modern textile characterization methods. Chapter 10 Objective Measurement of Fabric Hand, 1990; 329-353. 